\title{
High prevalence of Babesia microti in small mammals in Beijing
}

\author{
Chun-Yan Wei ${ }^{1 \dagger}$, Xiao-Mei Wang ${ }^{2 \dagger}$, Zhen-Sheng Wang ${ }^{1}$, Zhi-Hua Wang ${ }^{1,3}$, Zeng-Zhi Guan ${ }^{2}$, Lian-Hui Zhang ${ }^{1}$, \\ Xiang-Feng Dou ${ }^{2^{*}}$ (D) and Heng Wang ${ }^{1 *}$
}

\begin{abstract}
Background: Babesiosis is an emerging tick-borne zoonotic infectious disease. Babesia microti is responsible for most cases of human babesiosis globally. It is important to investigate the prevalence of $B$. microti in the mammalian host population of a specific region in order to elucidate mechanisms of pathogen transmission and to define geographic areas where humans face the greatest risk of exposure. The aim of this study is to understand the prevalence and genotypes of B. microti in the small mammals that are found in Beijing, China.

Methods: We trapped small mammals from all of the 16 urban, suburban, and outer suburban districts of Beijing during the years 2014, 2017 and 2018. Genomic DNA was extracted from the heart tissues individually and the Babesia $18 \mathrm{~S}$ rRNA gene was detected by PCR. The genotypes of B. microti were identified based on sequence alignments and phylogenetic analysis. The morphology of the parasites was observed under light microscopy. The risk factors were analyzed statistically based on both univariate analyses and multivariate logistic regression.

Results: A total of 1391 small mammals were collected. Positive infection of B. microti was detected in 12.1\% (168/1391) of small mammals from 15 out of the 16 districts. Both Kobe-type and U.S.-type B. microti, accounting for $9.5 \%$ and $2.7 \%$, respectively, were identified. Classic diverse morphologic forms of B. microti were observed. Specific types of ecological habitats including shrub areas, broad-leaved forest, and cropland were revealed to be risk factors associated with B. microti infection.

Conclusions: This study demonstrated the wide prevalence of B. microti infection in eight species of small mammals in Beijing, with Kobe-type more prevalent than U.S.-type. This study provides fundamental information for the development of informed prevention and control measures by public health authorities; the data gathered indicates a need for further monitoring of both clinical diseases in individuals presenting with babesiosis-like symptoms, as well as the infection status of ticks in high risk areas.
\end{abstract}

Keywords: Babesia microti, Genotype, Molecular epidemiology, Small mammal, Beijing, Tick-borne infectious disease, Risk factor

*Correspondence: beijingcdc@163.com; hengwang@pumc.edu.cn

${ }^{\dagger}$ Chun-Yan Wei and Xiao-Mei Wang have contributed equally to this work

1 Department of Microbiology and Parasitology, Institute of Basic

Medical Sciences, Chinese Academy of Medical Sciences \& School of Basic Medicine, Peking Union Medical College, 5\# Dong Dan San Tiao, Dongcheng District, Beijing 100005, China

${ }^{2}$ Institute for Infectious Disease and Endemic Disease Control, Beijing Center for Diseases Prevention and Control (Beijing Center for Preventive Medical Research), No. 16 Hepingli Middle Street, Dongcheng District, Beijing 100013, China

Full list of author information is available at the end of the article

\section{Background}

Human babesiosis is a worldwide emerging tick-borne zoonotic infectious disease [1-3]. It has become a public health concern with increasing numbers of human cases reported in all inhabited continents [4]. The causative agents are obligate intraerythrocytic protozoa of the genus Babesia [5, 6]. Among the known Babesia species infecting humans, Babesia microti is the most prevalent species [7], with cases reported from the Americas,

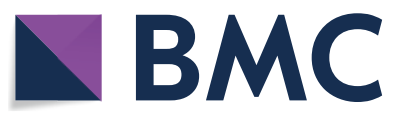

(c) The Author(s) 2020. Open Access This article is licensed under a Creative Commons Attribution 4.0 International License, which permits use, sharing, adaptation, distribution and reproduction in any medium or format, as long as you give appropriate credit to the original author(s) and the source, provide a link to the Creative Commons licence, and indicate if changes were made. The images or other third party material in this article are included in the article's Creative Commons licence, unless indicated otherwise in a credit line to the material. If material is not included in the article's Creative Commons licence and your intended use is not permitted by statutory regulation or exceeds the permitted use, you will need to obtain permission directly from the copyright holder. To view a copy of this licence, visit http://creativecommons.org/licenses/by/4.0/. The Creative Commons Public Domain Dedication waiver (http://creativeco mmons.org/publicdomain/zero/1.0/) applies to the data made available in this article, unless otherwise stated in a credit line to the data. 
Europe, Asia, and Australia [8]. Babesia microti is maintained in nature through an enzootic cycle that involves hard ticks of the family Ixodidae as the definitive host and a vertebrate as an intermediate host [6]. The primary reservoir hosts for $B$. microti are small rodents such as mice and voles $[9,10]$. Investigating the prevalence of $B$. microti in small mammalian hosts in a specific region is important in order to elucidate the mechanisms by which the pathogen spreads and to define geographic areas where humans are at risk of exposure.

Beijing, as the capital city of China, is the center for international exchange, tourism, and other activities, comprising a total of 16 districts, with two urban, ten suburban and four outer suburban districts. Beijing is surrounded by mountains on three sides and has a semihumid, seasonally temperature climate that is influenced by monsoon winds. Different geographical landscapes and vegetation distributions of Beijing make it a good natural environment for vectors and wild animals with pathogen reservoirs. Babesia microti infection in rodents from Beijing has been documented since 2013 [11, 12], but the whole picture of epidemiology for Babesia infection in small mammalian hosts in all 16 districts of Beijing were still largely unknown. The aim of this study is to understand the prevalence and genotypes of B. microti in the small mammals that are found in all 16 districts of Beijing.

\section{Methods}

\section{Study areas, samples collection, and DNA extraction}

Small mammals were captured by animal snap traps from all 16 districts of Beijing during the years 2014, 2017 and 2018. The sample sites represent five different ecological habitat types: (1) residential areas, (2) cropland, (3) shrub, (4) broad-leaved forest and (5) mixed coniferous and broad-leaved forest (mixed forest for short). The altitudes of sampling sites range from 20 to $1100 \mathrm{~m}$. Approximately 140-150 traps were placed every night at every sampling location for three consecutive nights. The species of trapped small mammals were identified based on their morphology referring to Chinese monographs [13, 14]. The gender, developmental stage, and environment of the captured mammals were recorded. After that the heart tissues were isolated individually and stored in liquid nitrogen until DNA extraction. Total genomic DNA of heart tissues was extracted using the Magnetic Beads Animal Tissue Genomic DNA Extraction Kit (Catalog number: NMG601, NanoMagBio Technology, China) according to the manufacturer's instructions. Briefly, about $5 \mathrm{mg}$ of heart tissue was isolated from each sample, and lysed at $68{ }^{\circ} \mathrm{C}$. The supernatant was then transferred to NanoMagBio S-96 automatic nucleic acid extraction platform with appropriate parameter settings. Finally, the genomic DNA was eluted in $50 \mu \mathrm{L}$ elution buffer and stored at $-20{ }^{\circ} \mathrm{C}$.

\section{PCR detection and phylogenetic analysis}

PCR targeting a specific fragment of Babesia 18S rRNA gene was performed using the primer pair BJ1/BN2 [15], which amplified fragments ranging 516-521 bp in length among different strains of $B$. microti according to sequences of the 18S rRNA genes of B. microti published in GenBank. Each amplification was carried out in a volume of $25 \mu$ l containing $12.5 \mu \mathrm{l}$ of $2 \times$ Phanta Max Master Mix (Catalog number: P515-01, Vazyme Biotech Co., Ltd, Nanjing, China), $1 \mu \mathrm{l}$ of genomic DNA template, $0.75 \mu \mathrm{l}$ of primers BJ1 and BN2 with each of $10 \mu \mathrm{mol} / \mathrm{L}$. The reaction mixtures were subjected to an initial denaturation step of $3 \mathrm{~min}$ at $95{ }^{\circ} \mathrm{C}$, followed by 38 cycles of denaturation at $95{ }^{\circ} \mathrm{C}$ for $15 \mathrm{~s}$, annealing at $57.5^{\circ} \mathrm{C}$ for $30 \mathrm{~s}$, and elongation at $72^{\circ} \mathrm{C}$ for $30 \mathrm{~s}$. Amplification was completed by a further step of $7 \mathrm{~min}$ at $72^{\circ} \mathrm{C}$. Genomic DNA isolated from B. microti strain Peabody mjr (Catalog number: PRA- $99^{\mathrm{TM}}$, ATCC) was used as the positive control and distilled water as the negative control. Amplicons were sequenced directly in both directions with the ABI 3730 xl DNA sequencing platform. Sequence alignments and analysis were carried out using DNAMAN version 7.0 (Lynnon Biosoft, San Ramon, USA). A search for homologous sequences was performed using the Basic Local Alignment Search Tool (BLAST) from the National Center for Biotechnology Information (NCBI).

For B. microti PCR-positive samples amplified using primer $\mathrm{BJ} 1 / \mathrm{BN} 2$, two overlapping fragments, with both longer than $1700 \mathrm{bp}$ in length, of the 18S rRNA genes were amplified by PCR amplifications. The near fulllength 18S rRNA gene sequences were obtained by assembly of the two large overlapping fragments. The primer pairs for the two amplifications were Piro1F/ rRNA3' and Piro2F/Piro6R [16, 17], respectively. The primer Prio2F was almost the same as Prio0F from reference [17] except the replacement of a "C" with "S". The conditions for amplifying the two large fragments were the same as those mentioned above except for the extension time in 38 cycles, which was 1 min $20 \mathrm{~s}$. Amplicons were also sequenced directly but using two more primers (Ba-SL and Ba-SR) besides the amplifying primers for full sequencing. Sequence assembly was performed using ContigExpress of Vector NTI Suite version 9.0 (Thermo Fisher Scientific Inc., Waltham, USA). All sequences of primers used in this study are listed in Additional file 1: Table S1; the diagram for illustrating the positions and length of primers, the amplified fragments and the near full-length 18S rRNA gene is shown in Additional file 2.

For phylogenetic analysis, nucleotide sequences of $18 \mathrm{~S}$ rRNA genes from another 34 isolates of B. microti from 
the USA, Europe, and Asia were included for comparison. Additionally incorporated were Babesia duncani WA1 from the USA, Babesia divergens from Europe, Babesia crassa-like pathogen (Babesia sp. strain H110), Babesia venatorum, and Babesia sp. XXB/Hangzhou from China, which were included as the outgroup. All sequences used in phylogenetic analysis were downloaded from GenBank and listed in Additional file 1: Table S2. The phylogenetic tree was constructed by the Neighbor-Joining method with the p-distance model as implemented in MEGA7 [18]. Phylogenetic analysis using maximum parsimony method was also conducted to examine the reliability of the resulting phylogenetic tree.

\section{Morphology observation of Babesia microti parasites}

Blood smears were made from captured animals from the district of Miyun in 2018. The smears were fixed with $100 \%$ methanol, stained with diluted Giemsa solution (Catalog number: SLBS0364, Sigma-Aldrich) for $10 \mathrm{~min}$; morphology observation was performed under a light microscope at $\times 1000$ magnification with oil immersion.

\section{Statistical analysis}

The association between sampling time, altitude of sampling sites, ecological habitats, developmental stages, genders of collected mammals, and Babesia microti infection were analyzed using univariate analyses based on chi-square $\left(\chi^{2}\right)$ test. The risk factors for $B$. microti infection were analyzed based on multivariate logistic regression. Significance level for all tests was set at $P<0.05$. All analyses were conducted using SPSS version 19.0 (IBM Corp, Armonk, USA).

\section{Results}

Prevalence of Babesia microti in small mammals in Beijing

A total of 1391 small mammals were trapped at 88 various sites from all of the 16 urban, suburban, and outer suburban districts of Beijing (Fig. 1, Table 1). The small mammals belong to the two orders-Rodentia and

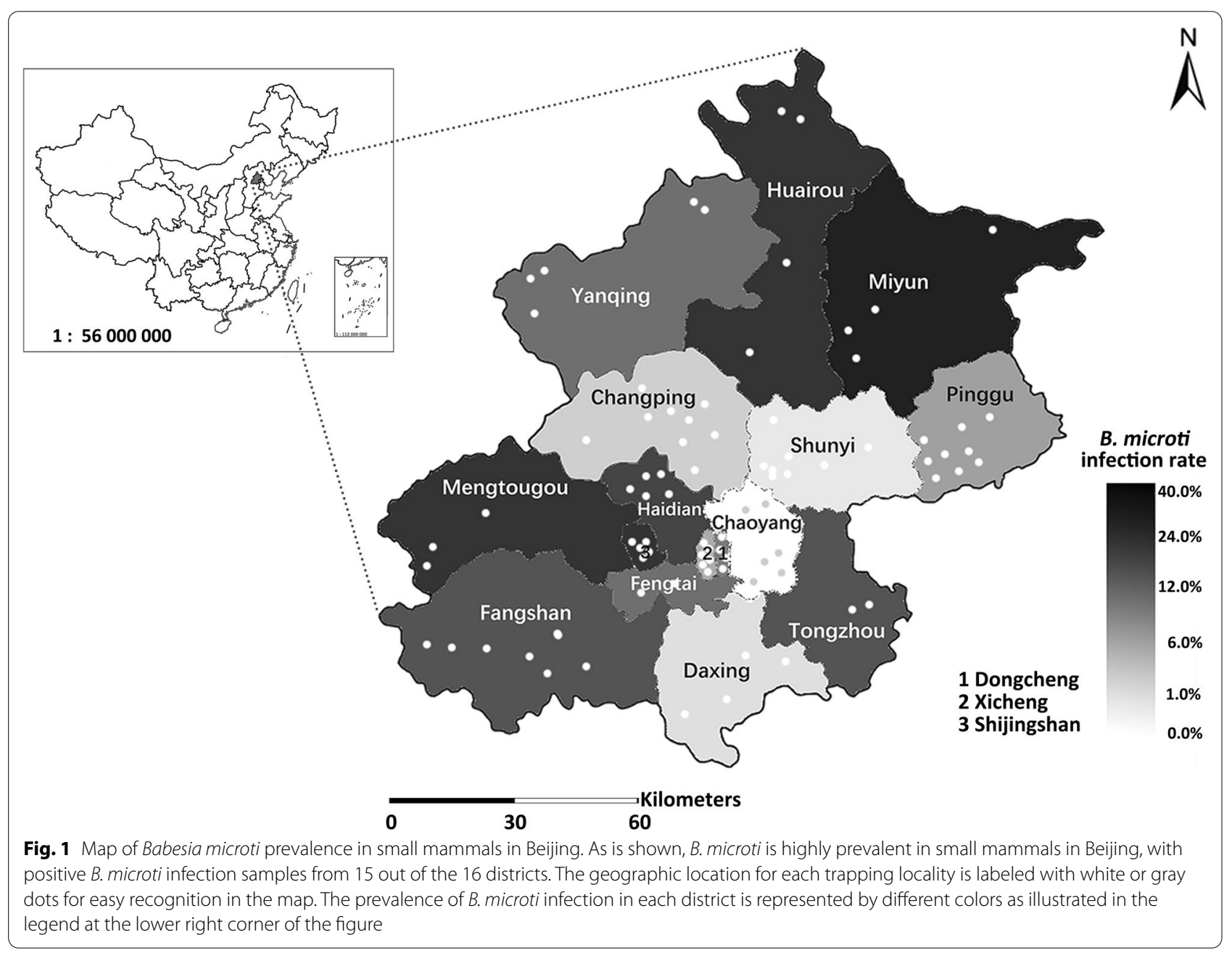


Table 1 Prevalence of Babesia microti in small mammals from different districts

\begin{tabular}{|c|c|c|c|c|c|c|c|}
\hline Districts & Regional type & $\begin{array}{l}\text { No. of mammals } \\
\text { tested }\end{array}$ & No. of positive & $\begin{array}{l}\text { Positive rate } \\
\text { (\%) }\end{array}$ & Odd ratio & $\begin{array}{l}\text { No. of Kobe- } \\
\text { type (\%) }\end{array}$ & $\begin{array}{l}\text { No. } \\
\text { of U.S.- } \\
\text { type (\%) }\end{array}$ \\
\hline Miyun & Outer suburban & 93 & $34^{*}$ & 36.6 & 56.47 & $31(33.3)$ & $4(5.4)$ \\
\hline Huairou & Outer suburban & 83 & 18 & 21.7 & 27.14 & $17(20.5)$ & $1(1.2)$ \\
\hline Mentougou & Suburban & 80 & 16 & 20.0 & 24.50 & $14(17.5)$ & $2(2.5)$ \\
\hline Shijingshan & Suburban & 67 & 13 & 19.4 & 23.59 & $13(19.4)$ & $0(0.0)$ \\
\hline Haidian & Suburban & 67 & 11 & 16.4 & 19.25 & $8(11.9)$ & $3(4.5)$ \\
\hline Fangshan & Suburban & 105 & 15 & 14.3 & 16.33 & $14(13.3)$ & $1(1.0)$ \\
\hline Tongzhou & Suburban & 78 & 11 & 14.1 & 16.09 & $10(12.8)$ & $1(1.3)$ \\
\hline Fengtai & Suburban & 59 & 6 & 10.2 & 11.09 & $2(3.4)$ & $4(6.8)$ \\
\hline Yanqing & Outer suburban & 120 & 12 & 10.0 & 10.89 & $5(4.2)$ & $7(5.8)$ \\
\hline Dongcheng & Urban & 105 & 10 & 9.5 & 10.32 & $3(2.9)$ & $7(6.7)$ \\
\hline Pinggu & Outer suburban & 121 & 8 & 6.6 & 6.94 & $6(5.0)$ & $2(1.7)$ \\
\hline Changping & Suburban & 141 & 9 & 6.4 & 6.68 & $6(4.3)$ & $3(2.1)$ \\
\hline Xicheng & Urban & 66 & 3 & 4.6 & 4.67 & $2(3.0)$ & $1(1.5)$ \\
\hline Daxing & Suburban & 59 & 1 & 1.7 & 1.69 & $0(0.0)$ & $1(1.7)$ \\
\hline Shunyi & Suburban & 99 & 1 & 1.0 & 1.00 & $1(1.0)$ & $0(0.0)$ \\
\hline Chaoyang & Suburban & 48 & 0 & 0.0 & & $0(0.0)$ & $0(0.0)$ \\
\hline Total & & 1391 & 168 & 12.1 & & $132(9.5)$ & $37(2.7)$ \\
\hline
\end{tabular}

*Among the 34 samples of Miyun, there was one sample infected by both Kobe-type and U.S.-type B. microti

Insectivora-and represent four families, eight genera, and nine species (Table 2). Sequence alignment showed that an average of $12.1 \%(168 / 1391)$ small mammals were positive for $B$. microti infection (Tables 1 and 2).

Among the nine species of trapped small mammals, the brown rat (Rattus norvegicus) accounted for the largest proportion of any species tested, comprising $55.8 \%$ $(n=776)$, whereas Myodes rufocanus made up the smallest proportion, representing only $0.3 \%(n=4)$. With the exception of the rock squirrels (Sciurotamias davidianus), eight of the nine species were found to be positive for B. microti infection. The B. microti positive infection rates ranged from $6.7 \%(52 / 776)$ of Rattus norvegicus to $33.3 \%(4 / 12)$ of the greater long-tailed hamster (Tscherskia triton) (Table 2).

Positive infected small mammals were found from all of the urban, suburban, and outer suburban districts except for the suburban district of Chaoyang (Fig. 1, Table 1). Rodents from the outer suburban district Miyun exhibited the highest B. microti infection rate of $36.6 \%$ (34/93), and the infection rates of small mammals from districts of Miyun, Huairou, Mentougou, Shijingshan, Haidian,

Table 2 Prevalence of Babesia microti in small mammals of different species

\begin{tabular}{|c|c|c|c|c|c|c|c|c|c|}
\hline Order & Families & Subfamily & Genus & Species & No. of tested & No. of positive & $\begin{array}{l}\text { Positive } \\
\text { rate }(\%)\end{array}$ & $\begin{array}{l}\text { No. } \\
\text { of Kobe- } \\
\text { type (\%) }\end{array}$ & $\begin{array}{l}\text { No. } \\
\text { of U.S.- } \\
\text { type (\%) }\end{array}$ \\
\hline \multirow[t]{8}{*}{ Rodentia } & Cricetidae & Cricetinaeh & Tscherskia & Tscherskia triton & 12 & 4 & 33.3 & $3(25.0)$ & $1(8.3)$ \\
\hline & & Arvicolinae & Myodes & Myodes rufocanus & 4 & 1 & 25.0 & $1(25.0)$ & $0(0.0)$ \\
\hline & Muridae & Murinae & Niviventer & Niviventer confucianus & 188 & $58^{*}$ & 30.9 & $51(27.1)$ & $8(4.3)$ \\
\hline & & & Apodemus & Apodemus speciosus & 120 & 19 & 15.8 & $14(11.7)$ & $5(4.2)$ \\
\hline & & & & Apodemus agrarius & 82 & 11 & 13.4 & $10(12.2)$ & $1(1.2)$ \\
\hline & & & Mus & Mus musculus & 197 & 22 & 11.2 & $13(6.6)$ & $9(4.6)$ \\
\hline & & & Rattus & Rattus norvegicus & 776 & 52 & 6.7 & $39(5.0)$ & $13(1.7)$ \\
\hline & Sciuridae & Xerinae & Sciurotamias & Sciurotamias davidianus & 7 & 0 & 0.0 & $0(0.0)$ & $0(0.0)$ \\
\hline Insectivora & Soricidae & Soricinae & Sorex & Sorex unguiculatus & 5 & 1 & 20.0 & $1(20.0)$ & $0(0.0)$ \\
\hline
\end{tabular}

${ }^{*}$ Among the 58 positive rodents of Niviventer confucianus, there was one infected by both Kobe-type and U.S.-type B. microti 
Fangshan and Tongzhou were significantly higher than that in Shunyi when it was used as a control (odds ratios: $56.47,27.14,24.50,23.59,19.25,16.33,16.09$, respectively; $P=0.000$ for all).

Near full-length 18S rRNA gene sequences were recovered from 59 out of $168 \mathrm{~B}$. microti positive samples in this study, comprising two unique sequences. The two sequences were deposited in GenBank with the accession numbers MT423326 and MT423327, respectively. There are 58 sequences, 1752 bp in length for each one, identical to MT423326, and one sequence, $1747 \mathrm{bp}$ in length, identical to MT423327. Phylogenetic analysis revealed that MT423326 and MT423327 belonged to Kobe-type and U.S.-type B. microti, respectively (Fig. 2).

In this study, Kobe-type B. microti was found to be the dominant population in Beijing (Fig. 3), as it was revealed

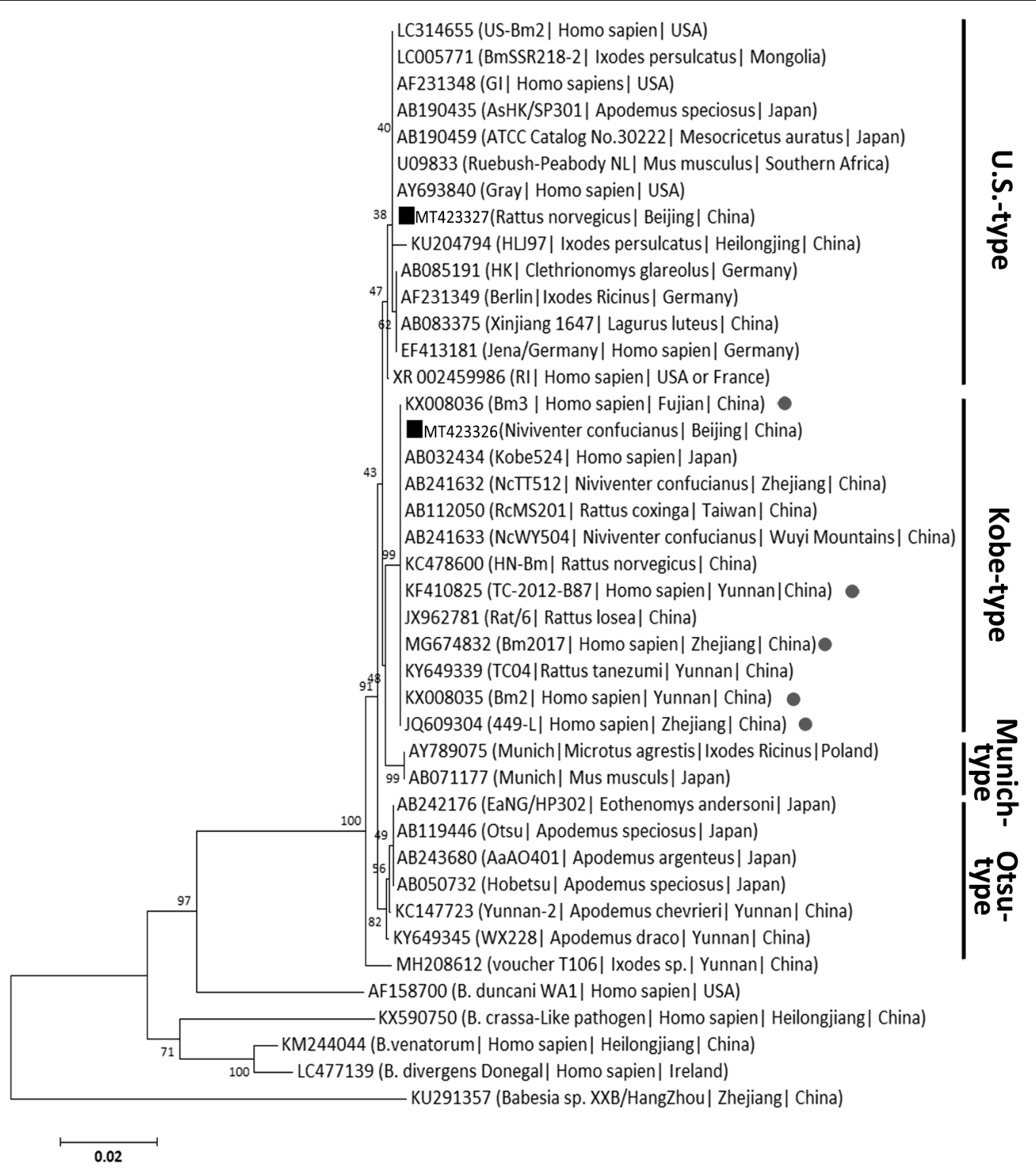

Fig. 2 Neighbor-joining phylogenetic tree based on the comparison of Babesia microti $18 \mathrm{~S}$ rRNA gene sequences obtained in this study with $B$. microti reference strains. Babesia duncani WA1, Babesia crassa-like pathogen (Babesia sp. strain H110), Babesia venatorum, Babesia divergens and Babesia sp. XXB/Hangzhou were used as the outgroup. The number on each branch denotes the percent occurrence in 1000 bootstrap replicates. Black squares stand for sequences identified in this study. Gray dots indicate human B. microti babesiosis in China. Branch lengths are drawn proportional to the estimated sequence divergence. Phylogenetic tree based on maximum parsimony method was also conducted to examine the effect of the resulting phylogenetic tree (data not shown) 

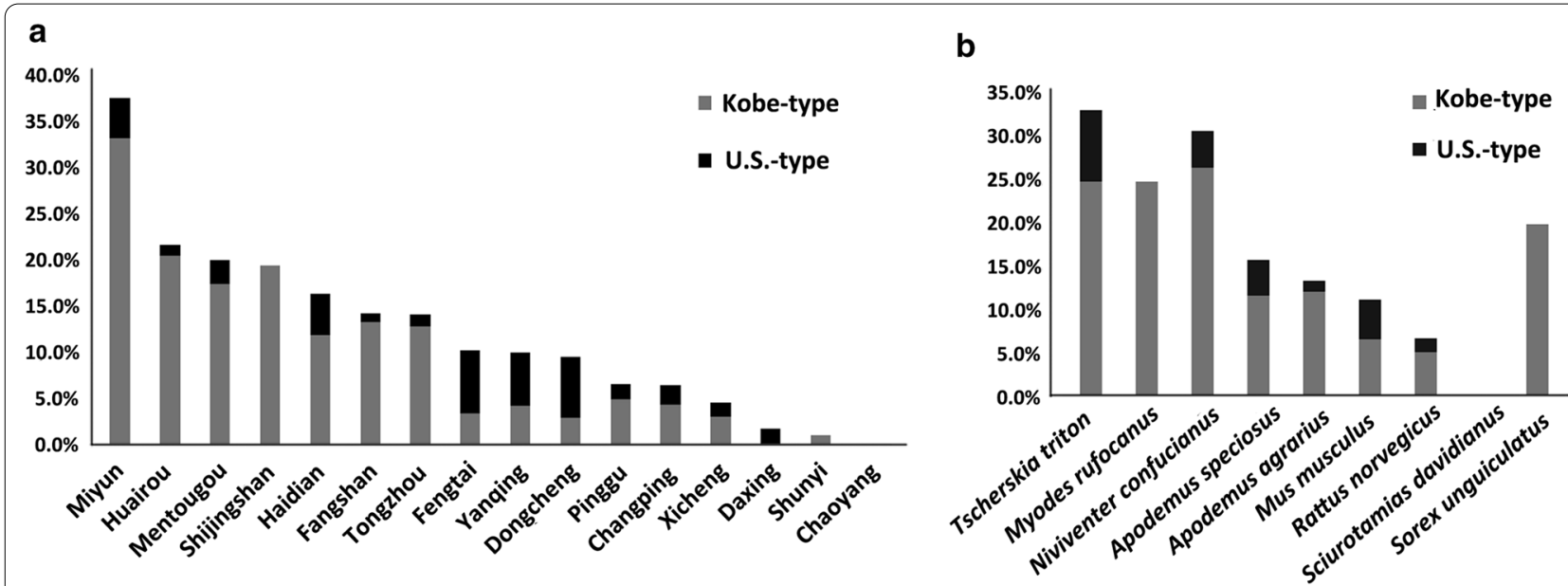

Fig. 3 Prevalence of both Kobe-type and U.S.-type Babesia microti from different districts (a) and in different reservoir hosts (b). The y axis represents the positive infection rate of $B$. microti in both $(\mathbf{a})$ and $(\mathbf{b})$, while the $x$ axes in $(\mathbf{a})$ and $(\mathbf{b})$ represent names of different districts and different species of small mammals, respectively. As is shown, Kobe-type B. microti is more prevalent than U.S.-type in nine out of the 15 positive districts (a) and in all of the eight species of small mammalian hosts (b)

to be more prevalent than U.S.-type in nine out of the 15 positive districts. The prevalence of the two types in the other five districts, including Dongcheng, Xicheng, Fengtai, Changping, and Yanqing (Fig. 3a, Table 1), was similar. The only positive sample detected in the suburban district of Daxing was the U.S.-type, which is the first demonstration of an existence of U.S.-type B. microti in this area. Kobe-type $B$. microti was also more prevalent than U.S.-type in all of the positive species, except for the house mouse (Mus musculus), for which the prevalence of the two types of B. microti was similar (Fig. 3b, Table 2). Furthermore, one rodent of Niviventer confucianus from the Miyun district was positive for both of the two genotypes of $B$. microti, demonstrating co-infection of different genotypes in some of the reservoir hosts.

\section{Diverse morphologies of Babesia microti}

Of the 33 samples from Miyun in 2018, 27.3\% (9/33) were confirmed to be positive for $B$. microti in blood smears, while $39.4 \%$ (13/33) were confirmed to be positive by PCR detection, reflecting the proven higher sensitivity of PCR than the microscopic methods in Babesia detection $[19,20]$. Classic diverse morphologic forms of B. microti parasites in erythrocytes of rodents were observed from the Giemsa-stained thin blood smears (Fig. 4), including dot form, ovoid form, ring form, pyriform, headphone form with two chromatin dots, Maltese cross form (also known as tetrad form), and ameboid forms, with the first five forms more commonly observed than the other two included in this study. In particular, the Maltese cross form was occasionally observed, although it is considered as a characteristic morphological feature of Babesia parasites in human babesiosis. In addition, this featured form seemed to appear more frequently in U.S.-type $B$. microti than in Kobe-type B. microti.

\section{The risk factors associated with Babesia microti infection}

The risk factors associated with Babesia microti infection in small mammals were analyzed from the perspectives of different sampling years, sampling altitude ranges, etiological habitats, ages, and genders of the small mammals (Table 3). Significant differences were present in all perspectives except in the sampling year. The prevalence of $B$. microti in male hosts (14.2\%) was significantly higher than that in female hosts $(P=0.029) ; B$. microti infection in adult hosts (13.3\%) was significantly higher $\left(X^{2}=8.88, P=0.003\right)$ than that seen in the pubertal ones $(6.2 \%)$ as depicted in Table 3. Notably, the prevalence of B. microti in small mammals from shrub areas, broadleaved forests, and cropland was $27.4 \%, 23.0 \%$, and $16.0 \%$, respectively, and each was significantly higher than that found from residential areas $(P<0.05$, Tables 3 and 4$)$. No difference was shown between $B$. microti infection from mixed forests and that from residential areas $(P=0.844$, Table 4). Further, the multivariate logistic regression analysis revealed that the altitude of $40-400 \mathrm{~m}$, adult life stage, and ecological habitats of shrub areas, broadleaved forest, and cropland were risk factors associated with the B. microti infection (Table 4). Interestingly, compared to broad-leaved forest, the mixed forest was not revealed as a risk factor, possibly because the coniferous plants might be a negative factor for the hosts to retain $B$. microti parasites, but further study needs to be done to elucidate this risk effect. 

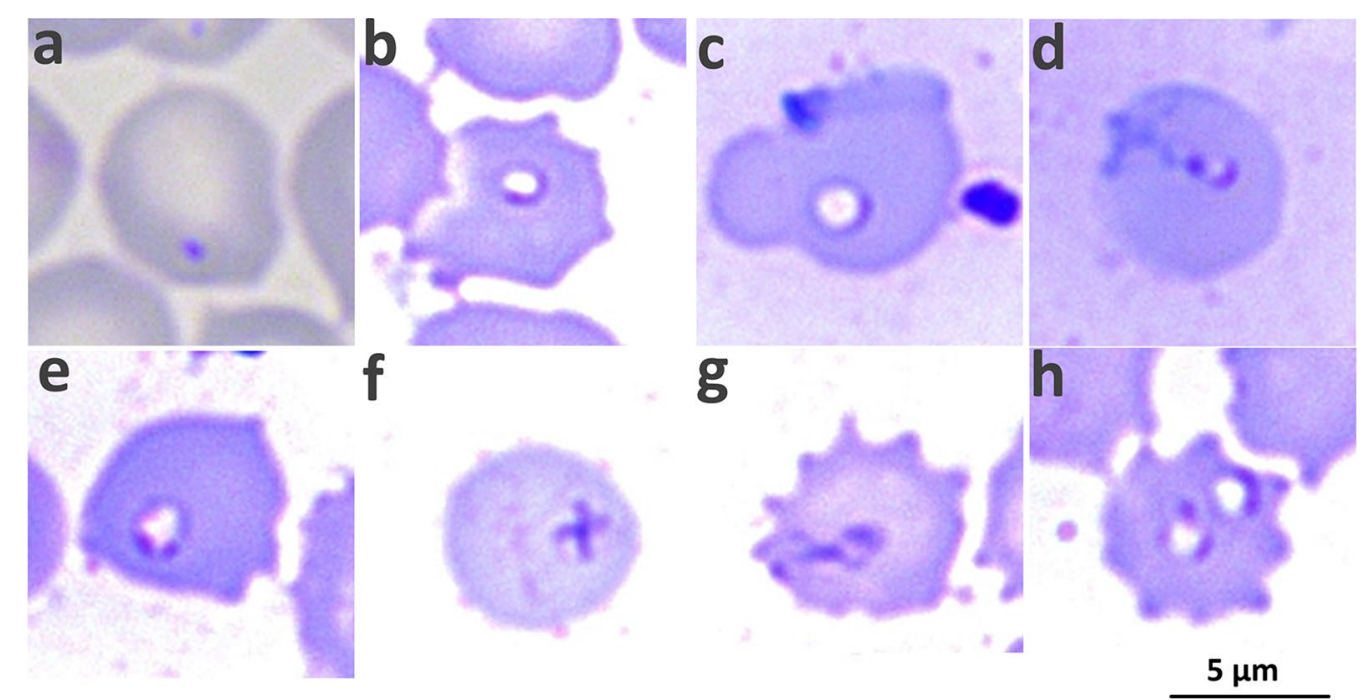

Fig. 4 Photomicrographs of Giemsa-stained thin smear blood films. As is shown, classic diverse forms of Babesia microti parasites in rodents' erythrocytes were observed, including dot form (a), ovoid form (b), ring form (c), pyriform (d), headphone form with two chromatin dots (e), Maltese cross form (also known as tetrad form) (f), and ameboid forms (g). Most of the infected red blood cell had one parasite (a-g), but two parasites in one red blood cell were also observed (h)

Table 3 Univariate analyses of risk factors related to Babesia microti infection

\begin{tabular}{|c|c|c|c|c|c|c|}
\hline \multirow[t]{2}{*}{ Variable } & & \multicolumn{2}{|c|}{ Sample size } & \multicolumn{3}{|c|}{ Babesia microti infection } \\
\hline & & Cases & $\begin{array}{l}\text { Constituent ratio } \\
\text { (\%) }\end{array}$ & Positive rate (\%) & $x^{2}$ & $P$-value \\
\hline \multirow[t]{3}{*}{ Year } & 2014 & 446 & 32.1 & 10.8 & 1.78 & 0.410 \\
\hline & 2017 & 419 & 30.1 & 11.7 & & \\
\hline & 2018 & 526 & 37.8 & 13.5 & & \\
\hline \multirow[t]{3}{*}{ Altitude (m) } & $\leq 40$ & 305 & 21.9 & 5.9 & 16.47 & $<0.001$ \\
\hline & $40-400$ & 903 & 64.9 & 14.5 & & \\
\hline & $>400$ & 183 & 13.2 & 10.4 & & \\
\hline \multirow[t]{2}{*}{ Gender } & Female & 514 & 39.4 & 9.9 & 4.77 & 0.029 \\
\hline & Male & 790 & 60.6 & 14.2 & & \\
\hline \multirow[t]{2}{*}{ Age } & Adult & 1149 & 82.6 & 13.3 & 8.88 & 0.003 \\
\hline & Pubertal & 242 & 17.4 & 6.2 & & \\
\hline \multirow[t]{5}{*}{ Ecological habitat } & Residential & 822 & 59.1 & 7.2 & 73.34 & 0.000 \\
\hline & Shrub & 135 & 9.7 & 27.4 & & \\
\hline & Mixed forest & 143 & 10.3 & 8.40 & & \\
\hline & Broad-leaved forest & 191 & 13.7 & 23.00 & & \\
\hline & Cropland & 100 & 7.2 & 16.00 & & \\
\hline
\end{tabular}

This table shows that significant differences were related to different altitudes, genders, ages, and types of ecological habitat of the small mammals, but not to different sampling years, based on the univariate analyses using Chi-square test

\section{Discussion}

This study was a systematical epizootic investigation of Babesia infection in small rodent and insectivore hosts from all of the 16 urban, suburban, and outer suburban districts of Beijing, and showed the wide prevalence of Babesia microti in small mammals in Beijing, with 15 districts harboring positive detection. Babesia microti infection failed to be detected in small mammals in Chaoyang, the only negative district, a finding possibly related to the smaller sample size in this area (Table 1). Previously, the existence of the hard ticks Ixodes persulcatus, Haematopus longicornus, and Haemaphysalis 
Table 4 Risk factors related to Babesia microti infection based on multivariate logistic regression

\begin{tabular}{llll}
\hline Variable & & OR $(\mathbf{9 5} \% \mathbf{C l})$ & $P$-value \\
\hline Altitude $(\mathrm{m})$ & $\leq 40$ & 1 & \\
& $40-400$ & $2.293(1.331-3.951)$ & 0.003 \\
\multirow{3}{*}{ Gender } & $>400$ & $1.071(0.476-2.410)$ & 0.868 \\
& Female & 1 & \\
Age & Male & $1.370(0.949-1.978)$ & 0.092 \\
& Pubertal & 1 & \\
Ecological habitat & Adult & $1.976(1.114-3.504)$ & 0.020 \\
& Residential & 1 & \\
& Shrub & $4.505(2.715-7.476)$ & $<0.001$ \\
& Mixed forest & $1.079(0.508-2.291)$ & 0.844 \\
& Broad-leaved forest & $3.406(2.057-5.638)$ & $<0.001$ \\
& cropland & $2.122(1.146-3.927)$ & 0.017 \\
\hline
\end{tabular}

This table shows that the altitude of $40-400 \mathrm{~m}$, adult life stage, and ecological habitats of shrub areas, broad-leaved forest, and cropland were risk factors associated with the $B$. microti infection based on the multivariate logistic regression

$O R$ odd ratio, $\mathrm{Cl}$ confidence interval

conicinna, which were vectors identified for $B$. microti infection in other provinces was documented [21]; these were indeed reported from several forest areas and scenic spots from six abovementioned districts, including three outer suburban districts of Miyun, Huairou, and Yanqing, and three suburban districts of Mentougou, Fangshan, and Changping [22-24]. The high prevalence of $B$. microti in small mammals from four out of the six districts in this study, strongly supports the hypothesis that there are important natural foci for human babesiosis in the four districts of Miyun, Huairou, Mentougou, and Fangshan, which demonstrated infection rates as high as $36.6 \%, 21.7 \%, 20.0 \%$ and $14.3 \%$, respectively. These unexpected results call attention to the neglected $B$. microti transmission cycle in Beijing, and as such, it is important to closely monitor the prevalence of $B$. microti in these districts. It is worth noting that neighboring districts do not always have similar prevalence of $B$. microti. For example, infection rate in neither Pinggu nor Shunyi, the two suburban districts, was detected to be over $10.0 \%$, although both of them were adjacent to the outer suburban district of Miyun, which presented the highest infection rate (Fig. 1 and Table 1). The similar phenomenon also occurred in Yanqing and Changping, both of which were neighboring to Huairou. These situations are probably attributable to different distribution and density of small mammals and tick vectors, as is known Miyun and Huairou have the most dense and abundant vegetations in Beijing, which might be more beneficial to the diversity and density of vectors and mammalian hosts.

Another unexpected finding was that the only two urban districts, Dongcheng and Xicheng, were also detected as positive for $B$. microti prevalence, although the infection rates were below the average, with $9.5 \%$ and $4.6 \%$, respectively. This finding may give novel clues to the only reported human babesiosis case from Beijing: a male patient living in Xicheng diagnosed with a Babesia infection [25], whose infection was highly attributed to a history of labor in rural areas of the adjacent Hebei province. For this case, infection via a local tick bite should be considered. It is also important to point out that there is no positive correlation between the high infection rate and the three different district types of outer suburban, suburban, and urban ones, as the fact that the six suburban districts, including Mentougou, Shijingshan, Haidian, Fangshan, Tongzhou, and Fengtai, presented higher infection rates than the two outer suburban districts of Yanqing and Pinggu did, and Pinggu even presented lower infection rate than the urban district of Dongcheng; the other three suburban districts of Daxing, Shunyi, and Chaoyang all presented lower infection rate than the only two urban districts did (Fig. 1 and Table 1). These phenomena might be related to the relationship between small mammals and their various ecological habitats, which does strongly suggest that monitoring the prevalence of $B$. microti should not be limited to wild environments; that in areas close to residents should also be paid intensive attention to. This finding implies that tick-borne diseases, are probably closer to human habitation than people thought. Additionally, further consideration should be given for any patient exposures to certain ecological habitat types-specifically broad-leaved forest, shrub, and cropland-as this study has shown that such exposure is considered to be an important risk factor (Tables 3 and 4). Ecological habitat type of forest was also found to be an important risk factor for $B$. microti infection in other studies in Yunnan [26, 27] and in Southeast Asia [28]. Thus, these findings show that forests, the natural habitat for ticks, likely represent areas of high risk for transmission of B. microti to humans, and as such, people either working in or traveling to the forest, should utilize adequate protection. Based on our findings, this study not only strongly suggests that the surveillance of $B$. microti prevalence in all the 16 districts of Beijing could not be overemphasized, but also calls attention to difficult clinical infections in patients who had a history of tick bites from at-risk areas. The development of informed prevention and control measures by the public health systems is urgently needed. Further detailed molecular identification of $B$. microti in ticks and residents should be imperatively included. 
Our present study revealed that both Kobe-type and U.S.-type B. microti were prevalent in small mammalian hosts from Beijing based on the large number of samples tested (Tables 1 and 2)-with Kobe-type more prevalent than U.S.-type. As is known, B. microti has been recognized as a genetically diverse complex group, generally clarified into U.S.-, Munich-, Kobe-, and Hobetsu- (or Ostu-) types [20, 28, 29]. In Beijing, only Kobe-type $B$. microti, was detected from small rodents in Miyun, and documented previously [11]. Hence, the identification of U.S.-type in this study revealed the genetic diversity of B. microti in small mammals in Beijing, as well as that in China as a whole. Previously, the most highly recorded genotype of $B$. microti was the Kobe-type, including those recorded from Yunnan [26, 27], Zhejiang, Fujian, and Taiwan [30, 31]. Babesia microti of Ostu-type was also detected from Yunnan province [26, 27]. U.S.-type B. microti was only reported from rodents from Xinjiang [16]. Thus, it is highly possible that U.S.-type is not the dominant population in China compared to the Kobe-type, a determination that would require further investigation with larger sample size and wider sampling areas. It is worth noting that human $B$. microti babesiosis reported in China was all clustered to Kobe-type $B$. microti (Fig. 2), implying the possible correlation between the $B$. microti infection in potential reservoir hosts and that as well in humans. It also implies the major responsible role of Kobe-type B. microti for human babesiosis in China, for which further focused correlational research needs to be conducted. In addition, a recent research study demonstrated that U.S.-type was more prevalent than Kobe-type B. microti in rodents from Southeast Asia including Thailand, Cambodia, and Lao PDR [28]. These data together show that the genotypes of B. microti in small mammals differ according to the different geographical regions investigated.

To our best knowledge, the greater long-tailed hamster (Tscherskia triton), has not been reported for B. microti infection before, while the other seven species involved in this study were reported in previous studies to serve as probable reservoir hosts for B. microti [11, 26, 31-34]. Our findings indicate the potential role of Tscherskia triton, with such a high infection rate of $33.3 \%$ (Table 2), for maintaining an enzootic cycle of $B$. microti, but further detailed studies are needed to confirm whether it is a reservoir host, an occasional host, or even an enhancing host. In addition, the co-infection with two different genotypes of B. microti in one Niviventer confucianus rodent was the first such co-infection identified by this study. It is possible that more co-infections will be uncovered with larger sample sizes. The co-infection prompts us to consider whether there are also dual infections occurring in humans, which would most certainly bring new challenges to the prognosis and the specific diagnosis for human babesiosis. This point deserves clinical attention, considering that little is known about the impact of coinfection on both virulence of the parasites and its possible correlation to clinical relapse.

There are some limitations of our study. (1) We did not choose nested PCR, which was used in many relevant investigations [27, 35]. However, the risks of contaminations during the performance of nested PCR are high, especially when the sample size is large (a total of 1391 samples in our study). Moreover, no significant difference in the sensitivity and that in the specificity between conventional PCR and nested PCR was reported in several other studies [36, 37]. (2) Near full-length 18S rRNA gene sequences, $1752 \mathrm{bp}$ for the Kobe-type and $1747 \mathrm{bp}$ for the U.S.-type in this study, were recovered from only $35.1 \%$ $(59 / 168)$ of the positive samples. As is known, it is more difficult to amplify longer fragments than the shorter ones. Furthermore, genomic DNA in this study was extracted from wild small mammals, which might harbor complicated pathogens, making it more interfering in recovering targeted genes of near full-length. Molecular detection methods with higher sensitivity and specificity are worth trying in the future study.

\section{Conclusions}

Our study revealed the wide prevalence of two genotypes of Babesia microti in small mammals collected from the outer suburban, suburban and urban areas of Beijing, with $B$. microti of Kobe-type more prevalent than U.S.type. This study provides fundamental data to support the development of informed prevention and other control measures that can be enacted by the public health authorities. The data demonstrates a need for further surveillance of humans with babesiosis-like symptoms, and further surveillance of the epidemiology of Babesia infection of ticks in these areas of interest. Further studies are needed to fully identify the impact of $B$. microti in Beijing. These would include: (1) both molecular and serological investigations into $B$. microti infection in local residents, (2) detailed detection and genetic identification of B. microti in ticks, and (3) deeper understanding of the transmission scenarios from small mammals to ticks and then to highly susceptible humans.

\section{Supplementary information}

Supplementary information accompanies this paper at https://doi. org/10.1186/s40249-020-00775-3.

Additional file 1: Sequences used in the manuscript. Table S1. Primers used in this study to amplify and to sequence the 18S rRNA gene sequences of Babesia microti. Table S2. All sequences used for phylogenetic analysis in this study. 
Additional file 2: Diagram for illustrating positions and length of sequences involved in recovering the near full-length $18 \mathrm{~S}$ rRNA gene sequences.

\section{Abbreviations}

DNA: Deoxyribonucleic acid; rRNA: Ribosome ribonucleic acid; PCR: Polymerase chain reaction; bp: Base pair.

\section{Acknowledgements}

We would like to thank all of the study participants for their commitment. We also specifically thank Prof. Xun Suo at College of Veterinary Medicine, China Agricultural University for careful reviewing the manuscript and acknowledge the support of staff at Institute for Infectious Disease and Endemic Disease Control, Beijing Center for Diseases Prevention and Control.

\section{Authors' contributions}

HW designed the whole study and contributed to reviewing the manuscript. X-FD contributed to study design, carried out statistical analysis, and participated in sampling collection. C-YW conducted the molecular biological detection, sampling acquisition, morphological observation, data analysis and drafted the manuscript. X-MW carried out the sampling acquisition and made blood smears. Z-ZG identified the small mammal species and helped the sampling acquisition. Z-SW, Z-HW and L-HZ participated in molecular biological detection. All authors read and approved the final manuscript.

\section{Funding}

This work was supported by funding provided by 1) Special Fund for Health Research in the Public Interest China (No. 201202019), 2) CAMS Innovation Fund for Medical Sciences (CIFMS) (No. 2016-I2M-1-019), 3) National Natural Science Foundation of China (No. 81401690), and 4) PUMC Foundation for Young investigator (No.33320140040). The funders had no role in study design, data collection and analysis, decision to publish, or preparation of the manuscript.

\section{Availability of data and materials}

The datasets collected and/or analyzed during the current study are available from the corresponding author upon reasonable request. Please contact author for data requests.

\section{Ethics approval and consent to participate}

Sampling in this research was approved by the Ethics Committee of the Beijing Center for Disease Prevention and Control, in accordance with the Regulation of the People's Republic of China for the Implementation of the Protection of Terrestrial Wildlife.

\section{Consent for publication}

Not applicable.

\section{Competing interests}

The authors declare that there is not any conflict of interest as for the publication of this article.

\section{Author details \\ ${ }^{1}$ Department of Microbiology and Parasitology, Institute of Basic Medical Sciences, Chinese Academy of Medical Sciences \& School of Basic Medicine, Peking Union Medical College, 5\# Dong Dan San Tiao, Dongcheng District, Beijing 100005, China. ${ }^{2}$ Institute for Infectious Disease and Endemic Disease Control, Beijing Center for Diseases Prevention and Control (Beijing Center for Preventive Medical Research), No. 16 Hepingli Middle Street, Dongcheng District, Beijing 100013, China. ${ }^{3}$ Department of Immunology, Guilin Medical University, Guilin 541000, Guangxi, China.}

Received: 18 August 2020 Accepted: 2 November 2020 Published online: 11 November 2020

\section{References}

1. Madison-Antenucci S, Kramer LD, Gebhardt LL, Kauffman E. Emerging tick-borne diseases. Clin Microbiol Rev. 2020;33(2):e00083-e118.

2. Gabrielli S, Totino V, Macchioni F, Zuniga F, Rojas P, Lara Y, et al. Human babesiosis, Bolivia, 2013. Emerg Infect Dis. 2016;22(8):1445-7.

3. Rozej-Bielicka W, Stypulkowska-Misiurewicz H, Golab E. Human babesiosis. Przegl Epidemiol. 2015;69(3):489-94.

4. Beugnet F, Moreau Y. Babesiosis. Rev Sci Tech. 2015;34(2):627-39.

5. Gray J, Zintl A, Hildebrandt A, Hunfeld KP, Weiss L. Zoonotic babesiosis: overview of the disease and novel aspects of pathogen identity. Ticks Tick Borne Dis. 2010;1(1):3-10.

6. Westblade LF, Simon MS, Mathison BA, Kirkman LA. Babesia microti: from mice to ticks to an increasing number of highly susceptible humans. J Clin Microbiol. 2017;55(10):2903-12.

7. Homer MJ, Aguilar-Delfin I, Telford SR 3rd, Krause PJ, Persing DH. Babesiosis. Clin Microbiol Rev. 2000;13(3):451-69.

8. Lemieux JE, Tran AD, Freimark L, Schaffner SF, Goethert H, Andersen KG, et al. A global map of genetic diversity in Babesia microti reveals strong population structure and identifies variants associated with clinical relapse. Nat Microbiol. 2016;1(7):16079.

9. Yabsley MJ, Shock BC. Natural history of zoonotic Babesia: role of wildlife reservoirs. Int J Parasitol Parasites Wildl. 2013;2:18-31.

10. Krause PJ. Human babesiosis. Int J Parasitol. 2019;49(2):165-74.

11. Wang ZS, Wang XM, Dou XF, Li X, Ren HL, Liu J, et al. First report of Babesia microti infection in rodents in Miyun district of beijing. Acta Parasitol Med Entomol Sin. 2013;20(4):218-21 (In Chinese).

12. Lv YN, Li LC, Dou XF, Chen LJ, Zhang XC, Guan ZZ, et al. An investigation on the harborage of three pathogens in small mammals in Beijing area, 2013. Chin J Vector Biol Control. 2016;27(4):336-9 (In Chinese).

13. Zhang RZ. Distribution of mammalian species in China. Beijing: China Forestry Publishing House; 1999.

14. Huang WJ. Rodents of China. Shanghai: Fudan University Press; 1995.

15. Casati S, Sager H, Gern L, Piffaretti JC. Presence of potentially pathogenic Babesia sp. for human in Ixodes ricinus in Switzerland. Ann Agric Environ Med. 2006;13(1):65-70.

16. Zamoto A, Tsuji M, Wei Q, Cho SH, Shin EH, Kim TS, et al. Epizootiologic survey for Babesia microti among small wild mammals in northeastern Eurasia and a geographic diversity in the beta-tubulin gene sequences. J Vet Med Sci. 2004;66(7):785-92.

17. Kawabuchi T, Tsuji M, Sado A, Matoba Y, Asakawa M, Ishihara C. Babesia microti-like parasites detected in feral raccoons (Procyon lotor) captured in Hokkaido, Japan. J Vet Med Sci. 2005;67(8):825-7.

18. Kumar S, Stecher G, Tamura K. MEGA7: molecular evolutionary genetics analysis version 7.0 for bigger datasets. Mol Biol Evol. 2016;33(7):1870-4.

19. Bawm S, Htun LL, Maw NN, Ngwe T, Tosa Y, Kon T, et al. Molecular survey of Babesia infections in cattle from different areas of Myanmar. Ticks Tick Borne Dis. 2016;7(1):204-7.

20. Wei Q, Tsuji M, Zamoto A, Kohsaki M, Matsui T, Shiota T, et al. Human babesiosis in Japan: isolation of Babesia microti-like parasites from an asymptomatic transfusion donor and from a rodent from an area where babesiosis is endemic. J Clin Microbiol. 2001;39(6):2178-83.

21. Fang LQ, Liu K, Li XL, Liang S, Yang Y, Yao HW, et al. Emerging tick-borne infections in mainland China: an increasing public health threat. Lancet Infect Dis. 2015;15(12):1467-79.

22. Zhao GP. Spatial distribution of ticks and their hazard prediction in China. Doctoral Dissertation. 2018.

23. Chen M, Fan MY, Bi DZ. A molecular epidemiologic investigation of north Asia fever in scenic spots of Beijing suburb. Zhonghua Liu Xing Bing Xue Za Zhi. 1997;18(4):197-200.

24. Li JM, Cao WC, Zhang XT, Wu XM, Dong ZY, Zhao QM, et al. Investigation on ticks and mice in forest areas of Beijing, China. Chin J Vector Biol Control. 2002;13(3):165-8 (In Chinese).

25. Wang H, Qi WJ. A case report of human Babesia infection in Beijing. Chin J Exp Clin Infect Dis. 2019;13(6):519-23.

26. Chen XR, Ye L, Fan JW, Li C, Tang F, Liu W, et al. Detection of Kobe-type and Otsu-type Babesia microti in wild rodents in China's Yunnan province. Epidemiol Infect. 2017;145(13):2704-10.

27. Gao ZH, Huang TH, Jiang BG, Jia N, Liu ZX, Shao ZT, et al. Wide distribution and genetic diversity of Babesia microti in small mammals from Yunnan province, Southwestern China. PLoS NegI Trop Dis. 2017;11(10):e0005898. 
28. Karnchanabanthoeng A, Morand S, Jittapalapong S, Carcy B. Babesia occurrence in rodents in relation to landscapes of mainland Southeast Asia. Vector Borne Zoonotic Dis. 2018;18(3):121-30.

29. Rar V, Yakimenko V, Makenov M, Tikunov A, Epikhina T, Tancev A, et al. High prevalence of Babesia microti "Munich" type in small mammals from an Ixodes persulcatus/Ixodes trianguliceps sympatric area in the Omsk region, Russia. Parasitol Res. 2016;115(9):3619-29.

30. Saito-Ito A, Takada N, Ishiguro F, Fujita H, Yano Y, Ma XH, et al. Detection of Kobe-type Babesia microti associated with Japanese human babesiosis in field rodents in central Taiwan and southeastern mainland China. Parasitology. 2008;135(6):691-9.

31. Xiao FZ, Peng XQ, Xu GY, Chen Y, Lin DH, Deng YQ. Investigation and genetic identification on Babesia infection in rodents in some areas of Fujian province. Zhongguo Ji Sheng Chong Xue Yu Ji Sheng Chong Bing Za Zhi. 2017;35(1):63-7 (In Chinese).

32. Tsuji M, Wei Q, Zamoto A, Morita C, Arai S, Shiota T, et al. Human babesiosis in Japan: epizootiologic survey of rodent reservoir and isolation of new type of Babesia microti-like parasite. J Clin Microbiol. 2001;39(12):4316-22.
33. Moustafa MAM, Taylor K, Nakao R, Shimozuru M, Sashika M, Rosa R, et al. Dynamics, co-infections and characteristics of zoonotic tick-borne pathogens in Hokkaido small mammals, Japan. Ticks Tick Borne Dis. 2016;7(5):922-8.

34. Hu MX, Zhang J, Fan DH, Fu WM, Sun XF. Detection of rodent infected by new tick pathogens in Suifenhe and Dongning ports. Chin J Vector Biol Control. 2009;20(6):573-6 (In Chinese).

35. Wang JM, Liu JL, Yang JF, Wang XX, Li Z, Xu JL, et al. The first molecular detection and genetic diversity of Babesia caballi and Theileria equi in horses of Gansu province, China. Ticks Tick Borne Dis. 2019;10(3):528-32.

36. Lee SY, Kim MJ, Kim MK, Wee WR. Comparative analysis of polymerase chain reaction assay for herpes simplex virus 1 detection in tear. Korean J Ophthalmol. 2013;27(5):316-21.

37. Kim HS, Kim DM, Neupane GP, Lee YM, Yang NW, Jang SJ, et al. Comparison of conventional, nested, and real-time PCR assays for rapid and accurate detection of Vibrio vulnificus. J Clin Microbiol. 2008:46(9):2992-8.
Ready to submit your research? Choose BMC and benefit from:

- fast, convenient online submission

- thorough peer review by experienced researchers in your field

- rapid publication on acceptance

- support for research data, including large and complex data types

- gold Open Access which fosters wider collaboration and increased citations

- maximum visibility for your research: over $100 \mathrm{M}$ website views per year

At BMC, research is always in progress.

Learn more biomedcentral.com/submissions 